\title{
CONFLICTOS ETNOPOLÍTICOS EN CHILE Y ARGENTINA. COMPARACIÓN DE LA SITUACIÓN COLONIAL DEL PUEBLO MAPUCHE 1860-1980
}

\author{
ETHNOPOLITICAL CONFLICTS IN CHILE AND ARGENTINA. COMPARISON \\ OF THE COLONIAL SITUATION OF THE MAPUCHE PEOPLE 1860-1980
}

\author{
José Luis Cabrera Llancaqueo*
}

\begin{abstract}
En este artículo se presentan los resultados de un estudio comparado acerca de las trayectorias históricas seguidas por el Pueblo Mapuche al iniciarse la situación colonial, derivada de las ocupaciones militares que los Estados de Chile y Argentina llevaron a cabo en su territorio en el siglo XIX. Utilizando modelos metodológicos comparativos que se sitúan en el plano de la interdisciplinariedad entre Historia y Ciencias sociales, se buscó establecer cómo el desarrollo de la situación colonial no solo dividió la integridad de un territorio políticamente autónomo, además de reducir al Pueblo Mapuche al estatus colonial de pueblo indígena, sino que también lo disoció al ser sometido por dos Estados, dificultando hasta 1980 la elaboración de una idea de libre determinación que contemplara la integralidad territorial.
\end{abstract}

Palabras claves: Pueblo Mapuche, Estado, conflicto etnopolítico, situación colonial, territorio.

This article presents the results of a comparative study on the trajectories history followed by the Mapuche People when the colonial situation began, derived from the military occupations that the States of Chile and Argentina carried out on their territory in XIX century. Using comparative methodological models that are located at the level of the interdisciplinarity between History and Social Sciences, it was sought to establish how the development of the colonial situation not only divided the integrity of a politically autonomous territory, In addition to reducing the Mapuche People to the colonial status of indigenous people, it also dissociated when submitted by two States, making it difficult until 1980 to develop an idea of self-determination that includes territorial integrity.

Key words: Mapuche people, ethnopolitical conflict, colonial situation.

\section{Introducción}

Chile y Argentina comparten una de las fronteras más largas del mundo, y también una historia de ocupación militar y colonialismo sobre los miembros y territorios de un mismo pueblo indígena: el Pueblo Mapuche, que en Chile habita mayoritariamente en la regiones del Biobío, La Araucanía, Los Ríos y Los Lagos, mientras que en Argentina las provincias de Chubut, Neuquén, Río Negro, Santa Cruz y Tierra del Fuego (Benclowicz 2012). A lo largo de esta historia compartida se han producido diversos conflictos etnopolíticos indígenas, identificándose diferencias entre ambos casos. Por ejemplo, siguiendo a Mario Góngora (1981), se puede establecer que en Chile el conflicto etnopolítico (Toledo 2005a) con el Pueblo Mapuche tiene una centralidad dentro del relato de la construcción del Estado, porque la consolidación del Estado chileno se debe a la tradición que portaban los hombres de armas que lo construyeron, cuyas capacidades se fueron perfeccionando en las batallas y los parlamentos que se daban en el contexto de la Guerra de Arauco. Por su parte, en Argentina el Pueblo Mapuche dista mucho de tener esta centralidad, ya que las pretensiones bonaerenses hacia el sur eran enormemente más bajas durante el dominio español. Diferencias como estas tendrán incidencia en la relación que las repúblicas chilena y argentina establezcan con el Pueblo Mapuche a partir del siglo XIX, incluyendo los proyectos de ocupación militar que desplegaron sobre su territorio. En este artículo se revisará la trayectoria histórica del Pueblo Mapuche desde el contacto con los españoles hasta la década de 1970, con el objeto de identificar los hechos que bifurcan el proyecto colonizador al producirse las independencias de Chile y Argentina. Con esta reconstrucción histórica se busca comparar las diferencias de los conflictos etnopolíticos que han influido en la disociación del Pueblo Mapuche tras la destrucción de su la integridad territorial.

* Instituto de Estudios Avanzados, Universidad de Santiago de Chile. Dirección postal: Román Díaz 89, Providencia. Santiago, Chile. Correo electrónico: Correojlcabrera@gmail.com 
Para ello la investigación se valió metodológicamente de una perspectiva interdisciplinar de metodología comparada, asumiendo la existencia de la confrontación inestable entre Historia y ciencias sociales planteada por Jaques Revel (1996). Según Durkheim (2001), para explicar los hechos sociales científicamente, se deben demostrar "comparando los casos en que se encuentren simultáneamente presentes o ausentes, e investigar si las variaciones que presentan en estas diferentes combinaciones de circunstancias, prueban que uno depende del otro" (p. 181). Asimismo, Bloch incorporó la perspectiva comparativa en la disciplina historiográfica, ampliándolo más allá del campo de la sociología en un esfuerzo por alcanzar la interdisciplinariedad. Para Bloch el método comparado consiste en buscar las similitudes y las diferencias que existen entre series de fenómenos de naturaleza análoga que han sido tomados de diferentes medios sociales. Por tanto, esta metodología consistente en "el estudio paralelo de sociedades vecinas y contemporáneas, constantemente influidas entre sí y sometidas precisamente en razón de su proximidad y de su sincronismo a la acción de las mismas causas en su evolución y que parcialmente tienen, al menos, un origen común" (Bloch 2008:117), resultó apropiado para la investigación de una sociedad indígena como la mapuche, que por causa del devenir histórico quedó dividida por la frontera de dos Estados modernos.

Primero, respecto de las técnicas metodológicas para realizar la comparación, la revisión bibliográfica contempló la producción de conocimiento especializada acerca de la relación Estado chileno y argentino/Pueblo Mapuche, donde se destacan los estudios respecto de conflictos étnicos, las políticas estatales hacia el Pueblo Mapuche y las consiguientes respuestas política y social de este. En segundo lugar, se revisó documentación como leyes y decretos de los Estados chileno y argentino de pueblos indígenas. Por último, se realizó una entrevista a la académica y activista mapuche Fabiana Nahuelquir, descendiente del connotado cacique mapuche de la Conquista del Desierto, Valentín Zayweke, para la reconstrucción del proceso político mapuche en Argentina.

En cuanto a estructura, en el primer apartado se exponen los elementos teóricos que permiten organizar los resultados propuestos en este artículo, explorando en la noción de lo indígena como el resultado de una empresa colonial y causante de conflictos etnopolíticos en el marco de la situación colonial que experimenta un pueblo sometido. En el segundo apartado se analizarán las relaciones que los mapuches establecieron con los españoles, incluyendo los enfrentamientos bélicos y la diplomacia, mientras que en el tercer apartado se analizarán las particularidades de la situación colonial del Pueblo Mapuche en Chile y Argentina hasta fines de la década de 1970, cuando los proyectos de las dictaduras militares representan una nueva amenaza para el Pueblo Mapuche y su territorio, generando respuestas disímiles en un lado y otro de la cordillera de los Andes. Finalmente, a modo de conclusión, se presentarán los resultados del ejercicio comparativo, relativos a las similitudes y diferencias en las trayectorias del Pueblo Mapuche en Chile y Argentina, perfilando las posibilidades de la integralidad territorial en un proyecto político de autonomía y libre determinación.

\section{Pueblos indígenas y conflictos etnopolíticos: condición para el colonialismo}

1. Lo indígena comprende todo aquello referido a una categoría, socialmente construida, que se le asigna a un pueblo y sus miembros por encontrarse sometidos al estatus de colonizados. Estos se diferencian étnicamente de la sociedad dominante, manteniendo sus propias formas políticas, sociales y culturales, como pueden ser un idioma, formas comunitarias de vida y una historia común que identifican en un territorio propio (Galdames 2000). El origen de este estatus de indígena se puede encontrar en la época de la conquista, la colonización o del establecimiento de las actuales fronteras estatales; por tanto, la construcción social del indígena y sus pueblos es aquella realizada por las sociedades y Estados modernos para diferenciarse de la población y formas de organización social que no habían mantenido contacto con la modernidad, los que transcurrido el tiempo derivó en exclusión y discriminación.

Los conflictos etnopolíticos indígenas serán aquellos en que un pueblo indígena se encuentra enfrentado a un Estado y una sociedad, donde está en juego la continuidad o la superación de la situación colonial en la que se encuentra. Por lo mismo, un conflicto etnopolítico no necesariamente hace referencia a los protagonizados por un pueblo indígena, sino que también lo son:

a) los conflictos interétnicos en que está en disputa el poder o control del Estado; 
b) los conflictos separatistas, de minorías nacionales cuyos movimientos etnonacionalistas se orientan a una estatalidad independiente;

c) conflictos y movimientos de minorías étnicas migrantes en países desarrollados; y

d) los conflictos, movimientos y contiendas por derechos de pueblos indígenas (Toledo 2005a: 69).

La conflictividad etnopolítica actual en el caso mapuche en Chile y Argentina es el resultado de la intervención de dos Estados modernos que no solo convirtió al Pueblo Mapuche en indígena, sino que bifurcó su trayectoria histórica al disociar a su población, lo que derivó en una nueva configuración colonial del conflicto etnopolítico en un contexto de situación colonial.

En América Latina se han producido tres formas en que se expresa el colonialismo: a) colonialismo como imposición de la soberanía en territorios conquistados, que para Sartre tiene un carácter sistémico y contiene en su interior elementos económicos, sociales y psicológicos; amalgamados en un sistema político que conserva la soberanía extranjera en un territorio conquistado (Sartre 1965). En esta forma de colonialismo existe una estructura política que establece el estatus jurídico de la población, instaurando un régimen político, jurídico y estatal colonial; b) colonialismo de colonos, donde la centralidad está en el accionar de los colonos como agentes del colonialismo, los que operan con dinámicas sociales propias que establecen a su llegada, sin obedecer a una planificación política llevada a cabo por un Estado extranjero que busca extender su dominación; c) colonialismo como expresión de relaciones sociales, esta forma remite a las relaciones de dominación colonizador/colonizado que se mantienen pese a la eliminación del régimen colonial formal. En el caso de los pueblos indígenas, la diferencia colonizadora se constituyó en torno a cuestiones raciales y formas de organización que no concordaban con el ideal de progreso moderno europeo del siglo XIX.

\section{Establecimiento de Relaciones Fronterizas e Intercambio Comercial}

1. Se calcula que antes de la llegada de los españoles, el Pueblo Mapuche habitaba desde el actual Valle Central chileno hasta la isla de Chiloé de norte a sur; mientras que en la orientación este-oeste, a partir del siglo XV se establecieron definitivamente desde el Atlántico al Pacífico. Este espacio territorial en la actualidad se denomina Wallmapu por los mapuches, siendo la parte chilena el Gülumapu y la argentina Puelmapu. Pese a la diversidad de identidades mapuches en su interior, existen elementos compartidos que cohesionan y permiten constituir un solo pueblo, p. ej. su idioma, el mapudungun, o ciertas creencias y mitos que van modelando los aspectos culturales. Con este panorama social y político se van a encontrar los españoles, destacándose el paso de los mapuches de un lado al otro de la cordillera, lo que no representaba la violación de un tratado o la vulneración de un territorio autónomo, ya que se realizaban para comerciar o establecer alianzas (Bello 2011).

En Gülumapu la relación entre las culturas hispánica y mapuche tuvo un carácter bélico en sus inicios, derivando en lo que historiográficamente se llama en Chile la Guerra de Arauco. Un hito histórico de esta se produce en 1598 con una gran insurrección que los españoles y la historiografía oficial han llamado Desastre de Curalaba, que es reconocida como una de las derrotas más grandes que un pueblo de América le haya propiciado a los españoles. La sublevación tuvo su fin en 1604, cuando los españoles cambian su estrategia y dan inicio a la llamada guerra defensiva, propiciada por el sacerdote jesuita Luis de Valdivia. Esta consistía en conquistar a los indígenas por medio de la evangelización, lo que se tradujo en la disminución de batallas que se entremezclaban con tiempos de paz en los que surgen los parlamentos o coyang, siendo el más importante el Parlamento de Quillin del 6 de enero de 1641. Al respecto Hernández (2003) señala que "los acuerdos surgidos de este parlamento, establecían el río Biobío como frontera entre dos naciones soberanas. Así, el 'territorio comprendido entre el Biobío y el Toltén se constituyó en una jurisdicción no perteneciente a la Gobernación de Chile (p. 104). La importancia de Quillin radica en que fue ratificado por el rey Felipe IV y su trascendencia histórica está en que se reconoce la soberanía que el Pueblo Mapuche mantenía sobre su territorio. Pinto Rodríguez (2009) señala que a partir de Quillin se produce "una complementariedad que contuvo el conflicto y favoreció las relaciones pacíficas" (p. 9) que dieron paso a un pacto colonial.

2. En cuanto al Puelmapu, antes de la creación del Virreinato de La Plata, el imperio español intentó 
en distintas oportunidades conquistar los territorios ocupados por diferentes pueblos, incluido los del Pueblo Mapuche, pero estos terminaron en fracasos. La estructura económica del imperio español privilegiaba la explotación de oro, fortaleciendo el desarrollo de ciudades como Lima y México, en desmedro de ciudades que carecían del mineral, como Buenos Aires (Gavira Márquez 2011). La situación cambia con las Reformas Borbónicas que reestructurarán la economía colonial española, las que introdujeron transformaciones políticoadministrativas que potenciaron a Buenos Aires (Halperin Donghi 1987:35-36). Entre 1778 y 1785, el virreinato del Río de La Plata constituyó sus primeras unidades jurídico-administrativas en la Patagonia, las que no mantuvieron regularidad. En 1785 el virreinato estableció la Comandancia de Patagones, un esfuerzo más sostenido para consolidar su posición, las que incluían fuertes militares e infraestructura. Sin embargo, la inestabilidad no se produjo por la amenaza de los indígenas, sino por las confrontaciones entre Buenos Aires y la Corona española, desembocando en el proceso independentista. En este contexto, la Comandancia de Patagones en 1814 quedó definitivamente bajo dominio rioplatense, pasando a integrar la provincia de Buenos Aires.

\section{Fin del pacto colonial e inicio de la situación colonial del Pueblo Mapuche}

1. En 1808 el imperio español comienza a debilitarse en Chile y la independencia iniciará el fin del pacto colonial, porque en el proyecto independentista existía un intento por incluir al mapuche en su interior. Sin embargo, esto último no pasó de ser un reconocimiento simbólico y esencialmente discursivo, porque en la práctica resultó ser todo lo contrario; es decir, exclusión (Pinto Rodríguez, 2000). En cuanto a lo territorial, en el itinerario de las elites se encontraba la idea de desconocer la soberanía del Pueblo Mapuche, pero la ocupación seguiría esperando el momento oportuno. Esto se verifica con el desconocimiento del Parlamento de Quillin incorporando en las primeras constituciones políticas el territorio mapuche con el nombre de Araucanía. Ahora bien, el Estado y sus instituciones no estaban presentes en el territorio, implicando la mantención de la soberanía del Pueblo Mapuche en él. Además, en 1825 el Estado republicano prolongó el pacto colonial con la firma en el Parlamento de
Tapihue, que mantuvo la jurisdicción de los caciques en sus territorios.

La situación cambia en 1852 cuando se crea la provincia de Arauco, el primer acto administrativo del Estado en territorio mapuche. En 1861 la ocupación militar se inicia con un debate acerca del estatus jurídico que tendrían los mapuches una vez concluida esta, en el que se resolvió conceder la ciudadanía a los mapuches. Así es como estos fueron incorporados a la nación chilena, a la vez que se rechazaban sus elementos étnicos diferenciadores, ya que se "proyectaba un Estado-nación políticamente centralista, unicultural y uninacional. O sea sin mezclas inconvenientes" (Tricot 2012: 87). Sin embargo, esta asimilación no logró la desaparición del Pueblo Mapuche, porque los conflictos étnicos que se han expresado a lo largo de toda nuestra historia republicana, demuestran que los pueblos indígenas siguen vivos en un país que muchas veces cree haberlos eliminado (Pinto Rodríguez 2000:7).

Además, también se debatió el estatus jurídico del territorio y el régimen de propiedad de la tierra que se establecería tras la ocupación. Para Toledo, esto es crucial, porque "que el Estado chileno proclamara su soberanía en territorio indígena... no implicaba necesariamente la negación de los derechos de propiedad indígena. No cabe confundir los conceptos de propiedad de las tierras con las jurisdicciones territoriales" (Toledo 2001:1129). La definición del debate se plasmó en la Ley de 1866, que erróneamente se ha interpretado como el instrumento utilizado para declarar propiedad fiscal las tierras ocupadas. En realidad esta ley creó el mecanismo para fijar los límites entre terrenos fiscales e indígenas: la Comisión de Ingenieros. Si esta no establecía la posesión mapuche de las tierras, estas quedarían baldías en un régimen de copropiedad entre el Estado y los mapuches hasta que llegara la Comisión Radicadora (Toledo 2001:1133). Sin embargo, este itinerario no se cumplía porque la Comisión de Ingenieros no esperaba el apersonamiento de la Comisión Radicadora, si no que declaraba fiscales las tierras sin esperar su deslinde, violando la ley de 1866 . Por tanto, la pérdida de la soberanía fue acompañada por un despojo llevado a cabo por agentes del Estado al margen de la ley. Con esto se concretó la situación colonial del Pueblo Mapuche en Gülumapu, por lo mismo, Caniuqueo (2006) señala que en la actualidad "nuestra historia y nuestra soberanía se encuentran suspendidas" (p. 129). 
Tras la invasión, el Estado estableció una normalización de la tenencia de tierras mediante el proceso de reducción territorial, asignando pequeños terrenos en un régimen de propiedad comunitaria que se aseguraba con los títulos de merced que en total representaban solo "el 5\% de los 10 millones de hectáreas que se nos reconocieron en los parlamentos" (Mariman et al. 2006:11). Esto tendrá un impacto en la sociedad y la cultura mapuche, p. ej.: a) los títulos de merced implicaron la introducción de un régimen de propiedad privada, diferente a como los mapuches separaban su dominios y posesiones; b) el régimen de propiedad privada y el capitalismo afectaron los sistemas de producción y acumulación de riqueza de los mapuches, que se basaba en la tenencia de animales al ser una sociedad ganadera; c) la economía mapuche se ve trastocada por la escasez de tierras de los títulos de merced, que no permitían desarrollar la economía ganadera forzándola hacia una agrícola, con lo que los mapuches terminaron formando parte de los sectores más pobres de una sociedad que la incluyó forzosamente.

El territorio mapuche no incluido en los títulos de merced representa "el 95\% restante que es parte del paisaje jurídico que se embolsaron los fundos, el mismo Estado, colonos (chilenos y extranjeros)..." (Mariman et al. 2006:11) La contrapartida del proceso de reducción fue la instalación y ampliación de la gran propiedad, la que con el correr del tiempo comenzó a expandirse, incluso, a costa de los títulos de merced. Por ello es que las reclamaciones a principios del siglo XX eran por tierras usurpadas, concepto que pasó a formar parte del vocabulario político mapuche, pese a que en un inicio hiciera referencia solo a la pérdida de los títulos de merced. En cuanto al impacto en la vida cotidiana de los mapuches, Pichinao (2015) plantea que "esta nueva forma de propiedad generó empobrecimiento, enfermedades y quiebres profundos al interior de las familias o lof (...) y fomentó las migraciones a los centros urbanos" (p. 89). Mientras que para Nahuelpan (2012) "el proceso de radicación (...) constituyó un proyecto eminentemente colonial. Como tal, no es casual que su terminología (título de merced, reducción, cacique) fue la misma que la usada por el gobierno colonial español en los siglos XVI y XVII" (p. 127).

Tras la derrota militar, el Pueblo Mapuche iniciará una etapa de resistencia frente a la relación colonial que promueve el Estado. Millaleo (2006) describe un escenario tradicional mapuche marcado por la autoridad de los ancianos, siendo una sociedad que se reproduce a sí misma por medio del traspaso de saberes desde ancianos a los jóvenes, algo determinante en el proceso de socialización primaria de los nuevos miembros y en la selección de liderazgos. Si bien las formas tradicionales de organización político-social permanecieron al interior de las reducciones, las formas modernas de educación penetraron de forma tal que los nuevos sujetos sociales tuvieran su socialización primaria en las escuelas y universidades chilenas, lo que tendrá más peso en la legitimación y selección de líderes.

Rolf Foerster y Sonia Montecino (1988) identifican un primer período de organizaciones mapuches que se inicia en 1910 y termina en la transición de las décadas de 1950 y 1960, cuando en el sistema político chileno se produce el avance de los sectores populares y la izquierda, momento en que jóvenes mapuches dan un giro estratégico y desarrollan vínculos con las fuerzas políticas y los sectores sociales que estaban en alza, distanciándose de las vinculaciones con fuerzas políticas conservadoras que predominaron durante el primer período de organizaciones mapuches. Una de las profundas transformaciones más radicales de esta época fue la reforma agraria y en ella el Pueblo Mapuche tuvo protagonismo. Entre 1960 y 1962 se desarrolla un movimiento de recuperación de tierras y, posteriormente, "con la implementación de la Reforma Agraria (1962-1973) se produjo un fenómeno muy interesante: el movimiento mapuche se reconfigura y, en alianza con los campesinos pobres no mapuche, logra constituir en la Araucanía un gran movimiento campesino e indígena" (Órdenes, 2016: 127).

La elección presidencial de 1970 marca un aspecto clave respecto de las formas de la acción política mapuche, reconfigurando el conflicto etnopolítico. Esto último debido a que la acción política comenzó a constituirse en clave de movilización al interior de las comunidades mapuches, y tras la "elección de septiembre de 1970, en la macrorregión sur se desplegaron múltiples movilizaciones mapuches que antecedieron a la toma de posesión de Allende. El episodio fue conocido como 'el Cautinazo', y fue un hito político" (Toledo 2005b:33). El Cautinazo y toda la movilización ocurrida desde 1968 reviste una importancia relevante en la configuración de los conflictos etnopolíticos, representando un salto cualitativo hacia la futura configuración de un movimiento autónomo. Además de esta rica experiencia organizativa, el proceso de reforma 
agraria dejó un importante registro de conquistas (Correa et al. 2005: 298).

2. Durante la Guerra de la Independencia de las Provincias Unidas del Río de La Plata, el territorio de la población originaria mantuvo la lejanía que tenía en la Colonia. Desde Buenos Aires se hicieron esfuerzos para mantener lejos del conflicto a los indígenas, apelando a la relativa paz que se había alcanzado en la época colonial, debido a que "el proyecto incluía, al igual que se planteaba en Chile, la idea de incorporar a los indios a la sociedad criolla, haciendo "de ellos una misma familia con nosotros"” (Ratto 2007:60-61). Sin embargo, para concretar la incorporación el gobierno bonaerense propició varios avances con la esperanza de que los indígenas mantuvieran la actitud pasiva, pero esto no ocurrió y las tensiones se agudizaron. En paralelo a esto comenzaba el proceso histórico que marcó profundamente la historia argentina durante el siglo XIX: los conflictos entre unitarios y federales que mantenía en constante tensión a Buenos Aires con las provincias.

Entre 1823 y 1825 la conflictividad etnopolítica alcanzó niveles sin precedentes debido al fortalecimiento de la política bonaerense de expansión hacia tierras fértiles, para dar abasto al incremento de la demanda externa. Los malones y represalias militares se sucedieron constantemente, sin que estos últimos resultaran eficaces para frenar las asonadas indígenas. Es así como surgirá la figura de Juan Manuel de Rosas, futuro gobernador de Buenos Aires e ícono del histórico conflicto entre Buenos Aires y las provincias. Su presencia política se consolidó en el marco del conflicto etnopolítico, cuando entra a escena luego que Brasil le declara la guerra a las Provincias Unidas del Río de La Plata en 1925, obligando a resguardar la frontera sur para concentrar las energías contra las fuerzas brasileñas. Así comienza lo que Ratto (2006) llama Paz Rosista, que logró disminuir la violencia sin alcanzar a hacerla desaparecer. Esta se sustentaba en la estrategia de Rosas de establecer relaciones personales con los líderes indígenas, ganando su confianza. Esto fue perdiendo eficacia después de que Rosas asumiera como gobernador de Buenos Aires en 1835, al mismo tiempo que se sumaban nuevos grupos indígenas que no se encontraban en el plan original de Negociación Pacífica de Indios, a causa de que en Walmapu la cordillera no representaba una frontera. El fin definitivo de la Paz Rosista llegó el 24 de febrero1853, con Rosas ya fuera de la gobernación, debido a un malón que aterrorizó a la población de Buenos Aires. Desde este hecho se fortalecerán las voces a favor de la ocupación militar del territorio indígena y su incorporación al territorio argentino, argumentando "que el avance se realizaría sobre un "desierto"” (Ratto 2006:18), utilizando la misma figura jurídica terra nullis con que la Colonia española había pretendido hacerse de ellos con anterioridad (Briones y Delrío 2007).

Distintas administraciones se necesitaron para madurar la idea de la ocupación, pero es durante la presidencia de Bartolomé Mitre (1862-1868) que se dicta la Ley $\mathrm{N}^{\circ} 215$ de Ocupación de Tierra en 1867, que en su articulado establecía:
Art. $1^{\circ}$ - Se ocupará por fuerzas del Ejército de la República la ribera del río 'Neuquén' ó 'Neuquen', desde su nacimiento en los Andes hasta su confluencia en el Río Negro en el Océano Atlántico estableciendo la línea en la margen Septentrional del expresado Río de Cordillera a mar.
Art. $2^{\circ}$ - A las tribus nómades existentes en el territorio nacional comprendido entre la actual línea de frontera y la fijada por el artículo $1^{\circ}$ de esta ley, se les concederá todo lo que sea necesario para su existencia fija y pacífica.

La Ley $\mathrm{N}^{\circ} 215$ también autorizaba una expedición general contra aquellos indígenas que se resistieran al sometimiento pacífico de las autoridades nacionales y a expulsarlas fuera de la nueva línea de frontera. El gobierno de Domingo Faustino Sarmiento (1868-1874), dando cumplimiento a la Ley $\mathrm{N}^{\mathrm{o}} 215$, avanzó con la frontera mediante negociaciones y acciones militares, mientras que su sucesor Nicolás Avellaneda (1874-1880) lanza una campaña encabezada por Adolfo Alsina en 1875 donde se movilizó a 3.700 soldados divididos en cinco columnas. Para llegar a este punto fue trascendental la figura de Sarmiento, no como político y jefe de Estado, sino como el ideólogo de un proyecto de desarrollo nacional que encontró su legitimación en el enfrentamiento a lo indígena, como sinónimo de barbarie.

En el liderazgo de la resistencia mapuche destacó Juan Kalfukura, cuya importancia en la historia mapuche se cimentó por la decisión de Rosas de recurrir a él para concretizar la Paz Rosista, al considerarlo "el hombre indicado para gobernar la 
Pampa" (Hernández 2003:145). La Confederación Mapuche bajo el mando de Kalfukura que logró mantener la soberanía de los mapuches tras el fin de la Paz Rosista, y sus momentos de mayor gloria fueron en la década de 1860 y mediados de la de 1870. Tras la derrota de San Carlos en 1872 y la muerte de Kalfukura en 1873 "los caciques designaron a Namunkura, heredero de las huestes de su padre, bajo el compromiso de imitar con denuedo su astucia en la lucha desigual que les sobrevendría" (Hernández 2003:145).

En 1877 el presidente Nicolás Avellaneda nombró al general Julio Argentino Roca a cargo de la campaña militar denominada Conquista del Desierto, clave en la instalación del colonialismo argentino sobre el Puelmapu, que impide a los relatos y fuentes indígenas de la campaña ser parte de la Historia Nacional Argentina. Por tanto, la influencia ideológica de Sarmiento en la historiografía y sociedad argentina, no desconoce la Conquista del Desierto ni el hecho de que esta se haya producido; sino que desconoce los alcances que para el Pueblo Mapuche tuvo. Ezequiel Adamovsky (2009) señala que: 'La 'Campaña del Desierto' que comandó Roca en 1879, en la que fueron exterminados varios miles de personas, fue el episodio más dramático de este genocidio, pero no el único" (p. 32).

Como se puede apreciar en la escritura de Adamovsky, existe un gesto que tiende a desmitificar la construcción de la historiografía argentina sobre los pueblos indígenas y la Conquista del Desierto: el reconocimiento de la campaña militar como un genocidio. En este sentido, para Lenton (2010) es la Ley 947 Sobre Distribución de Tierras del año 1878 la que configura el delito de genocidio, debido a que posibilitó "el financiamiento de la acción militar mediante un empréstito especial, ya que dicha expansión ya se había determinado mediante la Ley 215 de 1867" (p. 3). Es importante mencionar que la Ley 947 buscaba correr la frontera del Estado hasta Río Negro, otorgando el respaldo legal para el avance militar: "Ya iniciada la Campaña del Desierto de Roca, el Coronel Uriburu cruzó el río Neuquén el 12 de mayo de 1879 y entró en territorio de Sayweke violando un tratado, y en contra las órdenes explícitas del Congreso y del propio Roca (Lenton 2010:34-35). Son estos pactos no respetados los que comienzan a configurar el crimen de genocidio, porque "no solo fueron abandonados y traicionados sino también negados, hasta el punto de afirmarse en el Congreso Nacional, en 1885, que nunca habían existido los Tratados con los indios" (Lenton 2010:32).

Tras la Conquista del Desierto o genocidio indígena, el Pueblo Mapuche inicia su situación colonial en Puelmapu: "los Indios prisioneros y los reducidos voluntariamente comenzaron a transitar caminos diversos, cuyos destinos podían ser los ingenios y obrajes del norte argentino, el servicio doméstico en la ciudad de Buenos Aires o las reservas de la región patagónica" (Ratto 2007:202-203). Terminar en el servicio doméstico en Buenos Aires o en Reservas Indígenas en la Patagonia son dos ejemplos que muestran el carácter subordinado de la relación colonial establecida por el Estado. Esta distribución forzada de la población mapuche se aprecia en aquellos trasladados a La Plata como museos humanos y tratados como objetos exóticos. Como señala Mariman, "muchos de los líderes terminaron siendo expuestos, vivos como muertos, en los museos de Buenos Aires o Mar del Plata (...) Quizás uno de los casos más emblemáticos (...) sea el del lonko Inakayal" (Mariman 2006:113). Una segunda manifestación del colonialismo argentino fueron los traslados y asentamientos de familias en lugares apartados de su lugar de origen, que en algunos casos incluyeron campos de concentración transitorios, mientras el Estado fijaba la reserva definitiva.

Finalmente la situación colonial mapuche redujo la cuestión territorial de Walmapu a un problema de propiedad de las tierras, siendo muchas de ellas privatizadas en favor de aquellos que financiaron las campañas militares, mientras que otras fueron otorgadas a los altos mandos militares que habían participado en la guerra. También existieron tierras que fueron asignadas a comunidades indígenas en forma de radicación, para ello "se implementaron distintas formas legales de espacialización a base de percepciones diferenciadas de aboriginalidad que redimensionaron nuevas fronteras al interior de la nación" (Pérez 2016:127).

En tal sentido, a partir del testimonio de Nahuelquir (comunicación personal 2015) se pueden identificar cinco formas de origen jurídico de las tierras mapuches en Argentina, a saber: a) entrega de tierra al cacique: que correspondía a las reservas indígenas destinadas para aquellos caciques mapuches reconocidos como líderes por el Estado; b) radicación por premios militares: se entregaban a aquellas familias que habían participado en el conflicto bélico, a quienes se les premiaba por 
su participación, independiente del bando en que hubiesen participado; c) colonia mixta, mecanismo que era utilizado para asentar a indígenas y no indígenas, con la finalidad última que los indígenas se transformaran en ciudadanos o se civilizaran; d) alquila, que consistía en un alquiler en el que la familia indígena recibía un tratamiento igualitario a otros concesionarios no indígenas, debido a que no era obtenido por alguna legislación previa que los reconociera como indígena para ser radicado; e) permiso de ocupación precario, que eran contratos de arrendamiento otorgado por el Estado y debía renovarse todos los años. Para que esa renovación fuera posible se debía cumplir con algunas exigencias, como la introducción de ganado, plantar árboles o mejoras en general.

Estas formas de radicación estarán en el centro de los conflictos etnopolíticos, ya que las tierras comenzaron a ser amenazadas por terratenientes y colonos que buscaban expandir sus tierras productivas. De ahí que no sea un dato menor que la alquila como figura jurídica de asentamiento haya sido la más común, al no impedir la utilización de las tierras por no indígenas, produciendo una falta de certeza jurídica.

En las primeras tres décadas del siglo XX comienza a operar una burocracia que institucionaliza el problema indígena, donde se encuentra la Comisión Honoraria de Reducciones de Indios, una agencia indigenista encargada de regularizar las tierras indígenas que tuvo escaso éxito debido a la falta de certeza jurídica mencionada. Tras el derrocamiento de Hipólito Yrigoyen en 1930, el proceso político argentino durante el siglo XX se caracterizó por la alternancia entre gobiernos constitucionales y periodos de dictaduras militares, siendo la última de estas la que gobernó entre 1976 y 1983. En este largo período destacó el movimiento y proyecto político encabezado por Juan Domingo Perón, en el que "se propusieron desde el ejecutivo una serie de medidas con el objeto de atender a los requerimientos de la población indígena" (Hernández, 2003: 195), donde destacaron el fin de las atribuciones constitucionales del Congreso para la conversión de los aborígenes al catolicismo, y la sustitución de la Comisión Honoraria de Reducciones de Indios por la Comisión Permanente del Aborigen en 1948, que cesaría en sus funciones con el derrocamiento de Perón en 1955. En cuanto a legislación provincial, la Provincia de Neuquén, una de las con mayor población mapuche, sancionó en 1964 el Decreto-Provincial № 0737/64, que estableció 18 reservas mapuches con 10.000 hectáreas por asentamiento, las que vinieron a sustituir antiguas ocupaciones de precario.

A la última dictadura argentina le correspondió conmemorar el centenario de la Conquista del Desierto en 1979, en donde "el General Jorge Rafael Videla retomó la ideología del discurso del General Julio Argentino Roca. Cinco años después de las celebraciones del centenario de la 'Conquista del Desierto' comenzó la 'guerra abierta por el petróleo y la privatización del subsuelo" (Hernández 2003:201). En el plano provincial, la dictadura propinó un golpe simbólico al Pueblo Mapuche en la provincia de Buenos Aires al promulgar el Decreto-Ley 9.231, el que entregó en propiedad individual las tierras de Ignacio Coliqueo, último cacique mapuche bonaerense. Para Hernández (2003), "Se perpetraba, así, un nuevo ataque contra la tenencia colectiva de las tierras mapuche, y con él se socavaba, aún más, en este pueblo la pervivencia de su identidad y su cultura" (p. 203).

\section{Conclusiones}

Siguiendo el modelo comparativo de Bloch, la trayectoria del Pueblo Mapuche muestra una integridad territorial antes y después de la llegada de los españoles, debido a que la administración colonial de Chile fue detenida en su afán de conquista, viéndose forzada a establecer un pacto colonial que contempló la autonomía del Pueblo Mapuche, mientras que la administración colonial de Argentina no intentó la ocupación de los territorios mapuches, por lo que el Wallmapu mantuvo su dinámica económica independiente, habitado por diversas identidades mapudungun hablantes. No será hasta después de las independencias de Chile y Argentina que la autonomía mapuche se verá amenazada, y es en los planes de invasión donde se advierten diferencias que marcarán la bifurcación de la historia del Pueblo Mapuche. En Chile la invasión requirió de mayores consideraciones para organizarse, debido al reconocimiento como chilenos de los mapuches en la Guerra de Independencia y lo establecido en el Parlamento de Tapihue de 1825. En este sentido, la Ley de 1866 no fue respetada en sus disposiciones, porque el Estado actuó como si esta reconociera las tierras mapuches como fiscales, por medio de medidas administrativas ilegales. En Argentina, la Conquista del Desierto de Julio 
Argentino Roca se llevó a cabo bajo la doctrina terra nullis, sin reconocer derechos propietarios para los mapuches, considerados como población nómade que no cumplían con los requisitos que la doctrina occidental establece sobre la posesión (Bartolomé 2004).

La situación colonial del Pueblo Mapuche se inicia cuando los Estados de Chile y Argentina logran ocupar militarmente el Walmapu, suspendiendo su soberanía y reduciéndolo a pueblo indígena, lo que reconfiguró los conflictos etnopolíticos. En ambos países se vivieron procesos de reducción; es decir, titular a las comunidades, pequeñas porciones de tierra en las que podían desenvolverse con cierto apego a sus particularidades culturales, en un contexto general de migración, discriminación y marginalidad social. Sin embargo, las reducciones comienzan a verse amenazadas por intereses de colonos particulares que, amparados por las leyes del Estado, buscan apropiárselas para maximizar la producción. Tras una centuria de integración forzada a la institucionalidad, la organización política mapuche adquirió un bagaje sustantivo que resultará fundamental para el futuro proyecto de autonomía y libre determinación que se levantará desde la resistencia al neoliberalismo de la dictadura de Pinochet. En Argentina la invisibilización de los mapuches en la Conquista del Desierto y el efecto de las políticas indigenistas redujeron el conflicto etnopolítico a un litigio entre privados por la propiedad de la tierra (Seguel 2004). Estas diferencias en la configuración de los pleitos etnopolíticos demuestran que las acciones coloniales de ambos Estados disoció al Pueblo Mapuche, lo que comienza a revertirse a partir de la década de 1980, cuando el proyecto de autonomía y libre determinación se sustenta en la integridad del territorio mapuche configurado discursivamente como Walmapu (Martínez 2010).

\section{Agradecimientos}

Al programa de doctorado Procesos sociales y políticos en América Latina de la Universidad de Artes y Ciencias Sociales. A Fabiana Nahuelquir y Pedro Canales Tapia por facilitación de documentos e información relevante para el desarrollo de la investigación.

\section{Referencias Citadas}

Adamovsky, E

2009 Historia de la Clase Media Argentina. Apogeo y Decadencia de una Ilusión, 1919-2003. Editorial Planeta, Buenos Aires.

Bartolomé, M. A.

2004 'Los pobladores del 'desierto'. Genocidio, etnocidio y etnogénesis en la Argentina". Amérique latine. Historie et mémoire. Les cahiers ALHIM 10. Université Paris VIII, Paris.

Bello, A.

2011 Nampülkafe. El Viaje de los Mapuches de la Araucanía a las Pampas Argentinas. Ediciones Universidad Católica de Temuco, Temuco.

Benclowicz, J. D.

2012 "Migraciones y representaciones populares en una ciudad turística. Notas sobre San Carlos de Bariloche, Argentina". Diálogo Andino 40. Universidad de Tarapacá, Arica.

Bloch, M.

2008 [1999] Historia e Historiadores. Traducido por F. J. González García. Akal, Madrid.

Briones, C. y Delrío, W.

2007 La "conquista del desierto" desde perspectivas hegemónicas y subalternas. RUNA, archivos para las ciencias del hombre XXVII. Facultad de Filosofía y Letras, Universidad de Buenos Aires, Buenos Aires.

Cabrera Llancaqueo, J. L.

2016 "Complejidades conceptuales sobre el colonialismo y lo postcolonial. Aproximaciones desde el caso del Pueblo
Mapuche". Revista Izquierdas 26:169-191, IDEA/USACH, Santiago de Chile.

Caniuqueo, $\mathrm{S}$.

2006 "Siglo XX en Gulumapu: de la fragmentación del Wallmapu a la unidad nacional mapuche. 1880-1978". En ¡...Escucha Winka...! Cuatro Ensayos de Historia Nacional Mapuche y un Epílogo Sobre el Futuro, editado por P. Mariman, S. Caniuqueo, J. Millalen, R. Levil, pp. 129213. Lom ediciones, Santiago de Chile.

Durkheim, E.

2001 [1986] Las Reglas del Método Sociológico. Traducido por E. De Champourcín, Fondo de Cultura Económica, México.

Foerter, R y Montecino, S.

1988 Organizaciones, Líderes y Contiendas Mapuches (1900-1970). Centro de estudios de la mujer, Santiago de Chile.

Galdames, L. A.

2000 "Mito y Epistemología”. Diálogo Andino 19. Universidad de Tarapacá, Arica.

Gavira Márquez, M. C.

2011 "El mineral de Chayanta (Alto Perú): La sublevación indígena de 1781 y el auge minero". Diálogo Andino 37. Universidad de Tarapacá, Arica.

Góngora, M.

1981 Ensayo Histórico Sobre la Noción de Estado en Chile en los Siglos XIX y XX. Ediciones la Ciudad, Santiago de Chile. 
Halperin Donghi, A.

1998 [1969] Historia Contemporánea de América Latina. Decimotercera edición, Alianza editorial, Madrid.

Hernández, I.

2003 Autonomía o Ciudadanía Incompleta. El Pueblo Mapuche en Chile y Argentina. CEPAL/Pehuén Ediciones, Santiago de Chile.

Lenton, D.

2010 "La 'cuestión de los indios' y el genocidio en los tiempos de Roca: sus repercusiones en la prensa y la política". En Historia de la Crueldad Argentina. Julio A. Roca y el Genocidio de los Pueblos Originarios, editado por O. Bayer, pp. 29-49. Ediciones El Tugurio, Buenos Aires.

Mariman, $\mathrm{P}$.

2006 "Los mapuche antes de la conquista militar chilenoargentina". En i...Escucha Winka...! Cuatro Ensayos de Historia Nacional Mapuche y un Epílogo Sobre el Futuro, editado por P. Mariman, S. Caniuqueo, J. Millalen, R. Levil, pp. 129-213. LOM Ediciones, Santiago de Chile.

Mariman, P. Caniuqueo. S. Millalen, J. Levi, R.

2006 i...Escucha winka...! Cuatro Ensayos de Historia Nacional Mapuche y un Epílogo Para el Futuro. LOM Ediciones, Santiago de Chile.

Martínez, C.

2010 "Autonomía, esfera pública y alianza en la sociedad mapuche, siglos XIX y XX". En La autonomía a debate: autogobierno indígena y Estado plurinacional en América Latina, editado por González, M. Burguete Cal y Mayor, A. Ortíz-T. P. pp. 561-583. FLACSO-GTZ-IWGIA-CIESASUNICH, Quito, 2010.

Millaleo, A.

2006 Multiplicación, y multiplicidad de las organizaciones mapuche urbanas en la Región Metropolitana. ¿Incremento en la participación mapuche o fragmentación organizacional? Tesis para optar al título de Socióloga, Universidad ARCIS, Santiago de Chile.

Nahuelpan, $\mathrm{H}$.

2012 Formación colonial del Estado y desposesión en Ngulumapu. Ta iñ Fijke Xipa Rakizuameluwün. Historia y Resistencia desde el País Mapuche, editado por Comunidad de Historia Mapuche, pp. 119-152. Ediciones comunidad de Historia Mapuche, Temuco.

Órdenes, M.

2016 "Conflicto mapuche-campesino en La Araucanía: un análisis a partir de la estructura de oportunidades políticas. 1967-1973”. Revista Izquierdas 26:126-168. IDEA/USACH, Santiago de Chile.
Pérez, P.

2016 Archivos del Silencio. Estado, Indígenas y Violencia en Patagonia Central, 1878-1941. Buenos Aires, Prometeo libros.

Pichinao, J.

2015 "La mercantilización del Mapuche Mapu (tierras mapuche). Hacia la explicación absoluta". Awükan ka Kuxankan Zugu Wajmapu mew. Violencias Coloniales en Wajmapu, editado por E. Antieleo, L. Cárcamo-Huechante, M. Calfío, H. Huinca-Pitruin, pp. 87-105. Ediciones comunidad de historia mapuche, Temuco.

Pinto Rodríguez, J.

2000 De la Inclusión a la Exclusión. La Formación del Estado, la Nación y el Pueblo Mapuche. IDEA/ USACH, Santiago de Chile.

Ratto, S.

2007 Indios y Cristianos. Entre la Guerra y la paz en las Fronteras. Editorial Sudamericana S. A., Buenos Aires.

Revel, J.

1996 "Historia y ciencias sociales: una confrontación inestable". Revista Estudios Sociales 9: 11-20. Universidad Nacional del Litoral, Santa Fe.

Sartre, J.P.

1965 Colonialismo y Neocolonialismo. Situaciones V. Traducido por J. Martínez Alinari. Editorial Losada, Buenos Aires.

Seguel, A.

2004 Políticas Públicas y Pueblos Indígenas: El Caso de las Tierras Mapuche en Neuquén (Argentina) y la Araucanía (Chile). Estudios de Casos de Conflicto Público de Tierras y Recursos Naturales. Red de trabajo CLASPO.

Toledo, V.

2001 En segura y perpetua propiedad. Notas sobre el debate jurídico sobre derechos de propiedad indígena en Chile, siglo XIX. Actas del $4^{\circ}$ Congreso Chileno de Antropología, tomo II, pp. 1129-1139. Universidad de Chile, Santiago de Chile.

Toledo, V.

2005a "Políticas indígenas y derechos territoriales en América Latina: 1990-2004. ¿Las fronteras indígenas de la globalización?". Pueblos Indígenas, Estado y Democracia, editado por P. Dávalos, pp. 67-102. Buenos Aires, CLACSO.

Toledo, $\mathrm{V}$.

2005b Pueblo Mapuche, Derechos Colectivos y Territorio: Desafíos Para la Sustentabilidad Democrática. Programa Chile Sustentable, Santiago de Chile.

Tricot, T.

2013 Autonomía. El Movimiento Mapuche de Resistencia. Ceibo Ediciones, Santiago de Chile. 